\title{
Entre o diálogo e a discordância: um debate sobre as teses de Roberto Mangabeira Unger
}

\author{
[ Between dialogue and dissent: a discussion of the \\ theses of Roberto Mangabeira Unger
}

\section{William Melo ${ }^{\mathrm{I}}$}

\section{Fabiana Malha Rodrigues ${ }^{2}$}

RESUMO - Este artigo apresenta as principais teses do pensador Roberto Mangabeira Unger relacionadas a uma interpretação dos novos parâmetros da democracia ocidental, das instituições e da sociedade brasileira como um todo. Também desenvolve um diálogo com o autor, questionando alguns dos seus fundamentos. Mangabeira, ao pretender requalificar o debate sobre a democracia, a partir da adoção de novas alternativas institucionais, coloca-se num viés experimentalista. Utilizando-se de pressupostos marxistas numa mistura com pressupostos schumpeterianos, este autor é qualificado, nas palavras de Anderson (I992), como: "um profeta do primeiro mundo, a partir de uma abordagem filosófica do terceiro mundo". É nesse sentido que compreender suas teorias e dialogar/discordar tornam-se objetivos chaves deste trabalho. - PALAVRAS-CHA-

\begin{abstract}
VE - alternativas institucionais; democracia; sociedade brasileira - ABSTRACT · This paper discusses the importance of Roberto Mangabeira Unger's ideas, since he establishes new parameters for the occidental democracy, the institutions and the Brazilian society as a whole. His theory, by attempting to re-qualify the debate on democracy from the adoption of new institutional alternatives, expresses an experimentalist bias. Using Marxist assumptions with schumpeterian assumptions, the author is considered, in Anderson's (I992) words, as: "a prophet of the first world, from a philosophical approach of the third world”. In this way, understanding his theories and dialoguing/ disagreeing become key objectives of this work. - KEYWORDS - institutional alternatives; democracy; Brazilian society
\end{abstract}

Recebido em I8 de agosto de 2015

Aprovado em 07 de março de 2016

DOI: http://dx.doi.org/Io.II6o6/issn.23I6-90IX.voi63p202-2I8

I Universidade de Campinas (Unicamp, Campinas, SP, Brasil).

2 Fundação Centro Estadual de Estatísticas, Pesquisas e Formação de Servidores Públicos do Rio de Janeiro (CEPERJ, Niterói, Rio de Janeiro, Brasil.). 


\section{INTRODUÇÃO}

Ao estabelecer novos parâmetros para analisar a democracia e os atuais Estados, ditos como legítimos e abertos à contestação política³, Unger insere-se como um dos importantes teóricos no que se refere às novas abordagens, principalmente, no que diz respeito à "ressignificação" do que seria realmente um Estado democrático. Algumas de suas reflexões teóricas pretendem a realização de alternativas institucionais contemporâneas, em especial, levando em consideração o caso da realidade sociopolítica brasileira e de sua confrontação com a perspectiva ideológica da esquerda marxiana.

Assim, este artigo tem como um de seus objetivos expor seus pressupostos conceituais e estabelecer comparativos com demais teóricos 4 que imaginaram e esboçaram críticas e sugestões para o avanço do atual modelo político democrático que está, atualmente, legitimado em boa parte dos países ocidentais capitalistas.

Para isso, será analisada, antes de qualquer coisa, a factibilidade conceitual que escora a afirmação e o pressuposto da importância de alternativas institucionais; proposta realizada por Unger em quase todas as suas obras, onde este exalta a perspectiva da mudança institucional, como mola propulsora de um novo patamar democrático, levando-se em consideração principalmente seus impactos e propostas para mudança na formação social do Brasil.

Importante salientar que Unger, em consonância com autores que o influenciaram, tais como Stuart Mill, Marx, Proudhon e Herzem, defende um "novo projeto democrático". Entretanto, este rompe principalmente com as ideias marxianas, no que concerne à possibilidade de ruptura com o sistema. Outrora, nosso autor recusa confundir as aspirações de transformação com o que considera

3 DAHL, Robert. Prefácio à teoria democrática. Rio de Janeiro: Zahar, I989. Poliarquia: participação e oposição. São Paulo: Edusp, I997.

4 PATEMAN, Carole. Participação e teoria democrática. Rio de Janeiro: Paz e Terra, I992; DRYZEK, John. Deliberative democracy and beyond: liberal, critics, contestations. Oxford: Oxford University Press, 2000; DEWEY apud SABEL, Charles. Dewey, democracy and democratic experimentalism. Contemporary pragmatism, vol. 9, n. 2, 2012. 
premissas deterministas. Unger sustenta um "desentrincheiramento" das estruturas dos atuais modelos estatais que considera que levam a uma limitação da própria democracia.

Nesse sentido, não se pode classificar a obra de Unger como vinculada à escola da "desconstrução", porque sua própria teoria - de caráter construtivo, a nega em sua origem - reconhece que nossa liberdade de resistir, reimaginar e reconstruir os mundos sociais que habitamos é uma variável acessível na história. Classificá-lo como um antiliberal também não se pode fazê-lo, pois classifica sua teoria de "supraliberal", no sentido de que esta realiza as mais altas aspirações do liberalismo mediante a transformação de seus compromissos institucionais convencionais'.

Ou seja, este trabalho, ao apresentar as vertentes da tentativa de se pensar os pressupostos de novos modelos institucionais, em prol do fortalecimento de um estado democrático, também aborda a sua verossimilhança. Nesse intuito, cinco seções serão aqui expostas: quatro estabelecem diálogos com as reflexões do autor, e apenas uma, a última, ressalta as críticas e discordâncias com as teses de Unger. Dessa forma, este artigo se organiza da seguinte maneira: I) O diálogo: por uma teoria social rebelde; 2) A alternativa democrática, uma teoria social entre Proudhon e Marx; 3) A democracia mobilizadora de Unger; 4) A factibilidade do experimentalismo democrático no Brasil; e 5) A discordância: a perspectiva marxiana como contra-argumento.

\section{O DIÁLOGO: POR UMA TEORIA SOCIAL REBELDE}

A teoria social de Unger pode ser entendida como um esforço para levar ao extremo a ideia de uma "sociedade construída". Seus argumentos vão contra a possibilidade de uma sociedade feita e imaginada, já que esta é um artefato humano, e não a expressão de uma ordem natural fundamental - tônica que ele vai rejeitar em boa parte de seus trabalhos.

A ideia da sociedade artefato tem sua origem no Iluminismo, de acordo com o autor. Entretanto, as implicações dessas ideias foram elaboradas apenas pela metade, ou seja, o esforço de levar a ideia da "sociedade como artefato" ao limite foi bloqueado pela contratendência moderna de pressupostos da importância de desenvolver uma "ciência da história".

Nesse sentido, podemos refletir que na certeza da busca de uma "lei da história" podemos ter trazido, de acordo com Unger, um importante erro no que se refere à atual construção da teoria social moderna, "recheada" por uma apologia de uma "teoria social de estruturas profundas", sendo este um exemplo de pensamento social moderno a desenvolver uma "ciência histórica", rica em explicações de caráter procedimentalista. Ou seja, embora Unger estabeleça discussão e proximidade com os trabalhos de Marx, colocando-o como modelo de uma "teoria social estruturante", de corte profundo, ele também não poupa críticas às análises sociológicas de

5 UNGER, Roberto Mangabeira. A constituição do experimentalismo democrático. Revista de Direito Administrativo, vol. 257, p. 57-72, maio-ago. 200I. 
Durkheim e Weber, como autores cânones desta concepção teórica conceitual que, impreterivelmente, colocam o Estado e a sociedade civil, reféns de leis naturais e desenhadas como arquétipos construídos, influenciando e criando uma episteme sociológica de gênese positivista ${ }^{6}$.

De acordo com Unger, a "análise social de estrutura profunda" define-se por uma devoção aos três movimentos teóricos recorrentes: I) se dá pela tentativa de distinguir em toda a circunstância histórica um contexto, estrutura ou esqueleto formador, a partir das atividades rotineiras que o momento ajuda a reproduzir; 2) pelo esforço de representar a estrutura identificada em uma dada circunstância, como exemplo de um tipo de organização social repetível e indivisível; e 3) pelo apelo aos imperativos práticos e leis de transformação estabelecidas que inevitavelmente precipitem uma lista fechada ou uma sequência compulsiva de estruturas repetitivas.

Os compromissos com os três movimentos mencionados, de acordo com o autor, estão cada vez mais desacreditados pela própria experiência prática contemporânea. Por outro lado, a resposta a esta concepção teórica vem a partir de uma ciência social positivista que reflete sobre rotinas de conflito e compromisso, apenas dentro de um contexto institucional e imaginativo existentes. Dessa forma, os novos modelos adotados - também positivistas - deixam de notar o conflito em torno do contexto formador - a estrutura institucional e a possibilidade de esquemas imaginativos novos - aceitando, por sua vez, o contexto formador existente, passando a ver a sociedade através de uma visão resignada de processos, embutidos por membros provenientes de grupos privilegiados da sociedade.

As ideias políticas, assim como a real organização institucional do conflito pelo poder nas democracias liberais atuais, desencorajam a aliança do alcance com a especificidade. E o fazem pela negação das oportunidades de ligação contínua entre as disputas da política oficial e as querelas da vida diária. Fazem-no, geralmente, pela adoção de disposições institucionais que tornam a escolha entre ciclos de reforma e revolução uma das condições normais da vida civil. Assim, toda visão radical tem de ser imaginada como um desvio abrupto e total da sociedade existente e desenvolvida sem a influência punitiva da experiência e responsabilidades práticas.

Essa circunstância impõe uma visão limitada da estabilidade, reafirmando, assim, o dilema entre rotina e revolução. Mas também explica, de forma significativa, a qualidade estranha, onírica, de uma política que serve ao mesmo tempo para acomodar interesses mais grosseiros e para expressar a luta entre opiniões abstratas. A racionalidade econômica ampliada oferece aos interesses mais crus sua aparência axiomática e tornam explícita sua dependência da opinião. Não fosse por essa perturbação da concretude, a política partidária no sentido moderno nunca teria surgido, pois um de seus elementos mais cruciais, desde o início, foi o compromisso com princípios especulativos. Entretanto, esses princípios continuam em grande parte fragmentados e abstratos ou apenas esporadicamente se tornam concretos. Dessa forma, mesmo em circunstâncias de rotina e ciclos de reforma, as pessoas agem como se ofuscadas pela abstração. Sua conduta política de algo da arbitrariedade das facções confessionais agarra-se rigidamente a prescrições literais ou tateando ao

6 Idem, Necessidades falsas. São Paulo: Boitempo, 2005. 
acaso entre concepções do ideal, porque carecem de uma visão desenvolvida de uma realidade humana transfigurada7.

Tendo como pressuposto a pretensão da "teoria social de estrutura profunda", de ser a "ciência da história" e também as abordagens acríticas de uma ciência humana positivista, o pensamento social moderno passa a ficar limitado. O trabalho teórico de Unger, em síntese, passa a ser um esforço para levar a ideia da "sociedade construída" ao limite, para poder desenvolver uma teoria social radicalmente "antinaturalista" e "antinecessária”. Nesse sentido, a teoria social ungeriana coloca-se como uma teoria rebelde: contra uma teoria social clássica, que, pelo autor, é considerada uma herança funcionalista e determinista.

[...] precisamos eliminar algumas ideias errôneas encontradas na história do pensamento social, que têm limitado e solapado, nossa visão para com o fatal (mas não predestinado) caráter de nossas suposições institucionais e ideológicas. [...] chamo de teoria social estrutural profunda a essas concessões ao determinismo. E é a ele, ao determinismo e não a explicação funcional, ou ainda, o modo no qual se modela a explicação funcional, a quem imputamos os passos desastrosos e falsos das teorias sociais de maior influência nos últimos duzentos anos 8 .

\section{A alternativa democrática, uma teoria SOCIAL ENTRE ProudHon E MarX}

Unger verificará também que na contemporaneidade, em vez de as ações estatais desafiarem e reformarem as instituições das formas existentes de economia de mercado e da "pífia" democracia representativa, o programa do status quo econômico buscará apenas moderar as consequências sociais das divisões e hierarquias estruturais que passou a administrar. Ou seja, atualmente há uma social democracia conservadora, que defende a posição relativamente privilegiada da força de trabalho empregada pelas indústrias de produção em massa e intensivas ao capital, ao custo social da exclusão de um grande número de exilados em que parte da economia é marcada para privilégio de poucos. Desse modo, o establishment incorpora os programas sociais da social democracia, deixando o modelo passivo a mudanças, o que, para Unger, torna o atual modelo pernicioso.

A construção de sua teoria social tem, como se pôde verificar acima, um duplo objetivo: o de ser uma alternativa programática ao establishment econômico e, também, uma alternativa institucional a social democracia.

O cerne intuitivo da proposta do autor é o da reconstrução econômica na tentativa de substituir a demanda de garantia de emprego pelo aumento dos recursos e capacidades de cada trabalhador-cidadão, possibilitando, assim, a diversificação e descentralização radicais das formas de acesso às oportunidades produtivas. A

7 Idem, op. cit., maio-ago. 200I, p. 326.

8 Idem, op. cit., 2005, p. 3 I. 
primeira proposta dessa nova plataforma conduz, necessariamente, à generalização da herança social, por meio de contas de subvenção social a que todos terão acesso; a segunda, à desagregação da propriedade privada tradicional, recombinando e realocando seus elementos constitutivos. As duas propostas, por sua vez, devem ser sustentadas por instituições e práticas que incentivem a aceleração da política democrática e a auto-organização independente da sociedade civil. Os instrumentos tradicionais do constitucionalismo liberal são inadequados para a primeira proposta, da mesma forma que os direitos contratual e societário são insuficientes para alcance de sua segunda proposta'.

Sua tarefa mais árdua, no que se refere à sua teoria social, está inscrita quando propõe o desmembramento do direito de propriedade tradicional para atribuir seus componentes a diferentes tipos de titulares, mesmo que esses sejam um misto de empresas, trabalhadores, governos locais e nacionais, organizações intermediárias e fundos sociais ${ }^{\text {To }}$. Ao salientar que se opõem à reversão simples da propriedade privada convencional para a propriedade do Estado ou de cooperativas de trabalhadores, já que esta redefiniria a identidade do proprietário sem alterar a natureza da propriedade unitária, esta não chega a ser uma assertiva que abranda o impacto de sua proposta, já que sua concepção propõe uma estrutura de propriedade em três níveis: I) a criação de um fundo central de capital, criado pelo governo nacional democrático para tomar as decisões finais relativas ao controle social da acumulação econômica; 2) o estímulo à elaboração de vários fundos de investimentos, criados pelo governo e pelo fundo central de capital para aplicação de capital em bases competitivas; e 3) tomadores primários de capital, que passarão a ser as equipes de trabalhadores, técnicos e empreendedores. Subjacente a esse esquema, há uma correlação com as condições de crescimento econômico e os termos segundo os quais o crescimento econômico guarda gradações com o conceito de experimentalismo democrático estabelecido pelo autor ${ }^{\text {II }}$.

No que se refere à sua concepção mais desafiadora, é possível apreciarmos as ideias de Unger, tanto do ponto de vista da tradição da esquerda quanto da tradição liberal. Sob a perspectiva do pensamento radical democrático liberal, a teoria social de Unger relaciona-se com o radicalismo burguês de Proudhon. Dessa concepção nosso autor absorve a importância da ideia de descentralização econômica, de eficiência e a de democracia política. No que se refere à perspectiva da esquerda, este absorve e entende os dilemas intrínsecos e a instabilidade da pequena empresa cooperativa. Essa compreensão estimula nosso autor a reverter à versão tradicional do radicalismo emancipatório e descentralizado da política nacional, passando a desenvolver propostas de cooperação descentralizada entre governo e empresas. Essa concepção se adere às suas propostas de reformas criadas para acelerar a política democrática, por meio da solução rápida dos impasses entre poderes do Estado, para aumentar e manter o nível de mobilização política institucionalizada e para aprofundar e generalizar a auto-organização da sociedade civil.

9 Idem, op. cit., maio-ago. 200 .

Io Idem, ibidem.

II Idem, ibidem. 
O projeto de fortalecimento da democracia tem o objetivo de aprofundar o modelo democrático, democratizando o mercado e instrumentalizando o indivíduo. Por um lado, trata-se de liberalismo radical. Um liberalismo que sacrifica dogmas liberais sobre instituições políticas e sociais. Dogmas que os liberais têm tradicionalmente vinculados às expectativas sobre as possibilidades humanas. Por outro lado, trata-se de socialismo não estatal, outorgando conteúdo distinto e controverso à concepção de economia de mercado adaptável a princípios socialistas, hoje ideia tida como vazia de sentido ${ }^{\mathrm{T} 2}$.

Sua teoria social representa também um esforço em avançar a descentralização econômica e a liberdade individual, seu programa visa descentralizar e inovar a prática atual desenvolvida pelas concepções de mundo do estado neoliberal e da social democracia.

Sua teoria representa, nas palavras de Perry Anderson, um esforço para teorizar a "experiência desordenada, virando a mesa como profeta do primeiro mundo, a partir de uma abordagem filosófica do terceiro mundo"ז3. Ou seja, sua teoria investiga e incentiva formas de relacionamento humano prático e apaixonado que recombinem atividades tradicionalmente associadas a diferentes nações, classes, comunidades e papéis sociais. Essa sensibilidade aumentada, por sua vez, ajudaria a dar apoio às disposições institucionais do programa de democracia com autonomia, defendidas pelo autor. Dessa maneira, o programa institucional de Unger e sua visão de mudança da forma como as pessoas se associam seriam reforçadas mutuamente - uma se desenvolvendo pari passu o desenvolvimento da outra.

\section{A DEMocracia Mobilizadora de Unger}

Para além da construção de sua nova teoria social que se propõe como alternativa aos modelos ditos como construtivistas, Unger também propõe e ambiciona uma nova reconfiguração da democracia, já que o modelo atualmente em vigência parece não satisfazer o princípio de cidadania, participação e de igualdade de oportunidades.

A perspectiva ungeriana, nesse sentido denominada "democracia mobilizadora", vai além das perspectivas contemporâneas das ciências sociais e se traduz então a partir:

[...] [de uma] hipótese empírica que informa o programa da democracia mobilizadora [sendo] um esforço para realizar o ideal de grandeza - revigoramento coletivo e individual, em nosso vocabulário moderno -, que pode ser mais prontamente conciliado com o ideal cristão do amor, e com os compromissos igualitários e solidaristas que esse ideal ajudou a motivar. Na doutrina da democracia mobilizadora, encontra[remos] novas razões para afirmar as ligações entre as queixas mais importantes da sociedade moderna: de que somos desiguais, separados demais uns dos outros e pequeno demais. Descobri[remos] que, para repararmos as duas primeiras queixas, devemos reparar a terceira.

I2 Idem, op. cit., 2005, p. I6.

I3 ANDERSON, Perry. The zone of engagement. Londres: New Left Books, I992, p. 64. 
Em outra direção, a hipótese causal fortalece a pretensão do projeto da democracia mobilizadora em levar adiante a antiga esperança radical-democrática de explorar a área de intersecção possível entre as condições institucionais do progresso prático - principalmente do crescimento econômico - e as condições institucionais da independência do indivíduo da hierarquia extrema e arraigada. A causa do experimentalismo prático - e suas reivindicações por uma liberdade mais ampla de ajuste de estruturas - é o que esses dois projetos têm em comum. A democracia mobilizadora aposta na afinidade entre a flexibilidade que a inovação econômica e tecnológica permanente exige e o interesse humano numa experiência mais plena de liberdade ${ }^{\mathrm{I}}$.

Esse desenho da "democracia mobilizadora" guardará aproximações com os pressupostos de Dryzek ${ }^{15}$, que analisa a democracia deliberativa como a legitimação livre e desimpedida da população em todos os assuntos de interesse comum, nos quais estes não devem ser resumidos a espaços de participação. Ou seja, a qualquer tempo, discursos poderão ser mobilizados por quaisquer pessoas, não só em termos de decisões políticas, mas na prática cotidiana, nas relações sociais comuns, em locais de trabalho etc. Enfim, para Dryzek, que estabelece pressupostos importantes para a construção da "democracia mobilizadora" ungeriana, a democracia não deve se resumir a questão numérica de deliberantes. Esta deve ser livre, aberta e vinculada aos comportamentos tradicionais da população. A legitimidade para esse autor deve ser buscada na ressonância das decisões coletivas junto à opinião pública, Estado e demais autoridades.

Já no que se refere à concepção marxiana de democracia, esta também será aproveitada pela "democracia mobilizadora”; principalmente, o pressuposto de autodeterminação no mundo do trabalho como o centro do processo de exercício da

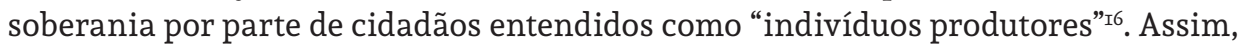
do enfrentamento surgido entre as concepções - liberais democráticas e marxiana -, três questões se farão necessárias para a formulação teórica de Unger, que são: I) a da relação entre procedimento e forma da democracia; 2) o papel da burocracia na vida democrática; e 3) a inevitabilidade da representação nas democracias de grande escala ${ }^{\mathrm{I} 7}$.

Por fim, mas não menos importante, a obra de Dewey ${ }^{18}$ apresenta também uma forte influência na construção teórica ungeriana, já que este autor valoriza a importância da relação mútua entre indivíduo e sociedade e o estabelecimento de um ideal de democracia como uma forma de governo que proporcione o desenvolvimento da inteligência social para a resolução de problemas, paralelamente à capacidade de crescimento do poder imaginativo individual. Suas ideias de democracia, que

\footnotetext{
I4 UNGER, Roberto Mangabeira. O direito e o futuro da democracia. São Paulo: Boitempo, 2004, p. I99.

I5 DRYZEK, John. Op. cit.

I6 PATEMAN, Carole. Op. cit.

I7 Este artigo não busca verificar a construção desses três pressupostos nas obras teóricas de Unger, entretanto, salienta-se o tema como relevante para pesquisas futuras sobre a obra deste autor.
}

I8 Apud SABEL, Charles. Op. cit. 
também se encontram em consonância com a "democracia mobilizadora", sofrem forte ascendência das duas exposições de ideal de democracia feitas por Dewey, a de que: I) a democracia como regime que mais encoraja a reflexão dos negociadores individuais sobre suas trocas espontâneas, podendo levá-los a canalizar seus resultados para o interesse geral; e 2) a democracia pensada, a partir das experiências locais e cotidianas, naturalmente faz surgir o espontaneísmo solidário e o autoconhecimento ${ }^{\mathrm{T}}$.

A construção da democracia mobilizadora é formada como um modelo híbrido entre a concepção liberal e a social democracia, já que sofre influência em sua construção de ideólogos liberais, teóricos críticos e marxianos ortodoxos. Seus impulsos são resumidos em basicamente duas perspectivas:

O primeiro impulso é o compromisso de introduzir na prática da democracia representativa alguns elementos da democracia direta. O conflito em torno do controle e dos usos do poder governamental deve assumir uma forma que ajude a aliviar o controle de interesses seccionais estreitos sobre a vida imaginativa da nação política. A tarefa consiste em atingir esse objetivo de forma que, ao contrário das formas tradicionais de plebicitarismo, populista, incentive a auto-organização independente da sociedade civil.

O segundo impulso motivador é o esforço de acelerar a política - mediante o favorecimento a programas decisivos em relação às segundas melhores soluções de cada partido -, oferecendo uma solução rápida para o impasse inibidor. O impasse inibidor resulta dos vetos formais que ramos independentes do governo se impõem uns aos outros, ou dos vetos informais que os poderes independentes da sociedade conseguem impor à ambição transformadora na política. Além disso, devemos tentar resolver o impasse mediante o engajamento do eleitorado geral, reunindo esforço de acelerar a política com a combinação das democracias direta e representativa. Temos que atingir esse objetivo de uma forma que garanta e aprofunde o pluralismo político-partidário e a liberdade política ${ }^{20}$.

Para além da definição dos impulsos que mobilizam o desenvolvimento da "democracia mobilizadora", sua proposta, de caráter inovador, ampliado e apologético, a criação imaginativa necessita de três pressupostos para se erigir: I) a necessidade do aumento da participação política; 2) a organização independente da sociedade civil; e 3) a importância da escola como protagonista de uma nova concepção de mundo, de caráter "criativo". Por outro lado, três riscos - identificados por Unger - também se encontram no caminho da "democracia mobilizadora": I) o risco de instabilidade: política forte, grupos fracos; 2) o risco da falta de ação: a ausência do agente da política inclusiva; e 3) o risco do conflito entre a necessidade pessoal e as exigências da democracia: o personalismo como "variável corrosiva" Ou seja, o experimentalismo democrático de Unger e suas demais construções teóricas, ao ser um desiderato de demais construções conceituais, ainda estão na

\section{I9 Idem.}

20 UNGER, Roberto Mangabeira. Democracia realizada: a alternativa progressista. São Paulo: Boitempo, I999, p. I70.

2I Idem. 
“fase das possibilidades”, a perspectiva colocada pelo próprio autor está em conseguir ultrapassar os desafios, vistos como riscos. De qualquer jeito, o desafio está posto; agora, é verificar quanto essa proposta é factível ou quanto é apenas um pressuposto ensaístico.

\section{A FACTIBILIDADE DO EXPERIMENTALISMO DEMOCRÁTICO NO BRASIL}

Ao abordar as obras de Unger, percebe-se um interesse especial do autor pela transformação da democracia e pelo direito constitucional, advogando sua gradativa substituição por novos paradigmas de transformações universais. Unger se utiliza de uma retórica sedutora para convidar seus leitores e debatedores para a proposta e liderança de um novo caminho - a partir da reconstrução institucional -, reivindicando um caminho próprio em detrimento de qualquer outro recomendado por países e culturas alheios as nossas, mesmo que o autor não exemplifique e esboce esse caminho de forma clara, muito menos planeie as instituições necessárias atreladas ao que ele denomina de novas experiências democráticas.

Seu grande objetivo, descrito para a realidade brasileira, é o de construir as condições políticas e constitucionais para a realização daquilo que a nação realmente reivindica, o que para ele é: “[...] transformar a democratização de oportunidades para aprender, trabalhar e produzir no próprio motor do crescimento econômico, ou seja, ancorando, portanto, as aspirações sociais na organização do econômico”22.

No experimentalismo democrático, não basta regular a economia de mercado. Não basta contrabalançar por meio de políticas sociais de transferência as desigualdades geradas no mercado. Nesse novo modelo de conceber a organização do Estado, torna-se fundamental e premente democratizar as oportunidades e instrumentalizar as energias frustradas e dispersas do povo brasileiro, canalizando-as para a reconstrução das instituições que definem a economia de mercado, o problema é como fazê-lo, pois nem Unger, nos define esses pré-requisitos.

Para compreendermos o poder desse projeto - a moeda comum entre liberais e socialistas nos últimos dois séculos - devemos entender a democracia como muito mais do que pluralismo partidário e do que responsabilidade eleitoral do governo perante um eleitorado amplo. Visto por um ângulo maior e mais revelador, o projeto democrático [é] o esforço de tornar a sociedade um sucesso prático e moral, pela conciliação da busca de dois gêneros de bens: o bem do progresso material, nos liberando da servidão e da incapacidade e dando asas aos nossos desejos, e o bem da independência individual, nos libertando dos esquemas triturantes de divisão e hierarquia social ${ }^{23}$.

O modelo concebido pelo autor tem como forte preocupação tornar o mercado mais inclusivo, a partir da redefinição dos atuais desenhos institucionais, reconstruindo assim as formas disponíveis para a coordenação estratégica entre Estado e

22 Idem, op. cit., 20II, p. 60.

23 Idem, op. cit., 2004, p. I6. 
produtores privados, e ampliar os regimes alternativos de propriedade privada e social, estes, por sua vez, coexistindo dentro da mesma economia de mercado. Nesse sentido, o experimentalismo democrático coloca o mercado como protagonista de grandes mudanças sociais, o que leva a crer que o desenho imaginativo ligado a esse modelo conceitual não opõe mercado à inclusão, ao contrário, acredita que são complementares.

No que concerne ao desafio mais fundamental, o experimentalismo democrático pretende desenvolver um novo momento de desenvolvimento para a realidade brasileira, já que a última grande reconstrução de estratégia de desenvolvimento que tivemos no Brasil ocorreu em meados do século passado.

Diferentemente da corrente marxiana que privilegia a consciência de classes para desmonte do arcabouço de dominação que representa o Estado capitalista e o mercado, a alternativa democrática incorpora a pressão popular, a partir de uma lógica organizada institucionalmente, não ficando claro, no entanto, quem na verdade ficaria a cargo dessa organização, mas ressaltando, todavia, que os interesses das maiorias desorganizadas devem ser ouvidos para que esta seja considerada.

O segundo grande objetivo do experimentalismo democrático é diminuir o vínculo entre mudança e crise. Para o autor, o fato de todas as sociedades contemporâneas, inclusive as maiores democracias de Estado, organizarem suas instituições de maneira a fazer com que a transformação continue a depender do trauma - o trauma na forma dos colapsos econômicos e o trauma na forma das guerras devem ser evitados.

É necessário, incorporar outra lógica no que se refere ao desenvolvimento do Estado, inscrevendo-se na necessidade de se evitar as crises decisivas. Não se deve contar com as grandes crises para serem parteiras das mudanças. Nosso autor acredita que as guerras, nesse mundo atual, ou serão guerras totais e devastadoras ou serão guerras localizadas, o que não proporcionaria nenhum tipo de avanço significativo ou novas concepções de desenvolvimento como foi possível de se verificar no século passado em países como Estados Unidos, França, Inglaterra, Alemanha e Japão.

As grandes crises de ruptura hoje não serão como as guerras que ocuparam a história moderna e que ajudaram a detonar transformações. As crises econômicas encontrarão alguma forma de reparo ou antídoto no ativismo dos Estados. Para os que defendem a possibilidade de alternativas institucionais, o objetivo se dá em organizar todas as instituições, em particular as instituições constitucionais, para que a transformação se torne endógena, interna, e deixe de depender das crises como sua circunstância favorecedora.

Tendo esses dois objetivos como uníssonos aos interesses universais da humanidade, estes serão naturalmente convergidos para um terceiro objetivo mais geral, que é o de acelerar e ampliar todas as formas do experimentalismo inovador e criativo nas sociedades contemporâneas. Essa ação faria surgir à concepção de estruturas que facilitam as inovações e que, inclusive, facultam sua própria transformação sem a dependência das crises.

Ao estabelecer esses novos parâmetros institucionais, emergiria então um novo paradigma de produção nas economias avançadas. Um paradigma de flexibilidade 
radical que atenua o contraste entre as tarefas de supervisão e de execução, que relativiza todas as especialidades, que mistura cooperação e concorrência e que se ancora no imperativo da inovação permanente.

Não podemos ser livres quando estamos fracos. A perversão do crescimento econômico e de seus frutos começa quando tentamos compensar a escassez de bens públicos produzindo mais bens privados e encontrar no consumo privado um consolo estéril para a frustração social. [...] Crucial a todos os aspectos do progresso material é a relação entre cooperação e inovação. Inovação exige cooperação. Não obstante, toda a forma real de cooperação permanece incrustada em estruturas que geram expectativas estabelecidas e direitos adquiridos de diferentes grupos, uns em relação aos outros. As pessoas em geral resistem à inovação porque temem, acertadamente, que ela ameace tais direitos e expectativas ${ }^{24}$.

Assim, a factibilidade do experimentalismo democrático se escora na suposição dos grandes interesses da humanidade como propulsora de desenvolvimento, já que, para Unger, não basta o Estado ofertar liberdade de economia de mercado para a sociedade. Além disso, na concepção advinda das novas alternativas institucionais, pesam também os interesses sociais e morais em atenuar as divisões e as hierarquias rígidas das sociedades contemporâneas que continuam a se dividir em sociedade de classes. Seu argumento, por fim, coloca em evidência e sobrevaloriza o interesse espiritual em poder participar, de corpo e alma, em um determinado novo mundo social - ainda não realizado, não esboçado e ainda a se erigir.

\section{A DISCORDÂNCIA: A PERSPECTIVA MARXIANA COMO CONTRA-ARGUMENTO}

Unger definitivamente coloca a importância de repensarmos a sociedade e sugere como possibilidade a tentativa de criações alternativas institucionais, necessárias para a atualidade, por dois motivos: I) a falta de iniciativas no que concernem às mudanças e 2) a ausência de um impulso desenvolvimentista para a grande maioria dos atuais estados democráticos. A explicação dada para essas consequências na atualidade e sua importância, de acordo com o autor, é que este novo caminho traçado possibilita alterar o atual estado de estagnação em que vivemos. Inscrito, principalmente, a partir do momento em que o capitalismo se tornou hegemônico e os pressupostos socialistas - “à esquerda” - passaram a perder importância conjuntural.

Para Unger e demais ideólogos do "experimentalismo”25, os estados que adotaram

24 Idem, op. cit., I999, p. I5.

25 SOUZA, Jessé. A invisibilidade da desigualdade brasileira. Belo Horizonte: Editora da UFMG, 2006; A ralé brasileira: quem é e como vive. Belo Horizonte: Editora da UFMG, 2009; Os batalhadores brasileiros: Nova classe média ou nova classe trabalhadora?. Belo Horizonte: Editora da UFMG, 20I0; A tolice da inteligência brasileira: ou como o país se deixa manipular pela elite. São Paulo: Leya, 20I5; TEIXEIRA, Carlos Sávio. A esquerda experimentalista: A análise da teoria política de Unger. Tese de doutorado. São Paulo: Universidade de São Paulo, 2009; ALTAMIRA, César. Os marxismos do novo século. Rio de Janeiro: Civilização Brasileira, 2008. 
o socialismo não conseguiram estabelecer um dinamismo ou mesmo a melhoria da qualidade de vida para sua população, principalmente a União Soviética, que se viu presa a uma economia planificada, com forte presença do poder estatal, com uma burocracia muito extensa e com a pecha de estabelecer um gigantismo de Estado para se impor ao sistema capitalista.

No que se refere às considerações da visão de nosso autor sobre o socialismo existente, este considera que o modelo adotado - de caráter centralizador e planificado - fracassou em seu intento ulterior, sendo importante a presença de uma alternativa, não de ruptura, mas interna. Entretanto, antes de adentrarmos nos pressupostos defendidos por Unger, uma questão se faz necessária: será que os “experimentalistas” estão corretos em seus pressupostos?

O que será agora exposto é que a crise em que o movimento socialista ingressou, desde meados da década passada, especialmente no Ocidente, pode ser objeto de outras considerações e que, na verdade, dificilmente será realizada uma transição para uma democracia mais inclusiva e progressista, sem a necessidade ao menos de ruptura com a classe hegemônica que se encontra no poder, principalmente no caso brasileiro, no qual a elite é plutocrática, concentradora de renda e de conhecimento.

Nesse sentido, o ideário socialista deve ser entendido como um período de transição para uma nova era histórica, que se caracteriza pela superação da propriedade privada em favor de uma nova forma de propriedade individual, baseada na socialização dos meios de produção. Esta deveria ter correspondido, no plano político, a uma democracia ampliada e participativa, dirigida à imensa maioria da sociedade. Esses acontecimentos de fato não ocorreram na história mundial, como bem salienta Unger em suas obras de I999, 2004 e 2005.

Entretanto, é preciso compreender que o socialismo também é parte integrante dessa nova era histórica, do mesmo modo que o capitalismo comercial e manufatureiro integra a história geral do capitalismo.

Nesse sentido, o socialismo ocorrido não estabelece aderência ao socialismo preconizado por Marx, como também não impede a sua realização futura. Os países que aderiram a um "pseudossocialismo" nada mais são do que um pressuposto de transição, advindos tanto do modo de produção que está nascendo quanto daquele já existente, que se formam não mediante a combinação de ambos, mas, principalmente, através do enfrentamento e da luta entre eles. A história desse período é a dos êxitos e dos fracassos do novo modo de produção e da classe que o representa em sua projeção para o futuro, haja vista as conquistas obtidas com a social-democracia, que surgem como paliativos ao medo de um real espectro que rondava a Europa, como também a constatação de atos totalitários por parte de países vinculados ao socialismo real.

Tratando-se, assim, do socialismo, isso é ainda mais verdadeiro. O capitalismo, cujo fundamento é um tipo específico de propriedade privada, iniciou sua existência dentro do modo de produção feudal. Foi necessário certo tempo para que a ordem feudal se apresentasse como obstáculo para o seu desenvolvimento. Foi então que a revolução burguesa e a conquista do poder se colocaram como inevitáveis. E, ainda assim, mesmo que as condições sociais existentes dificultassem que o capitalismo se concretizasse, este pôde seguir seu caminho, ainda que por vias mais tortuosas, até a extinção total do regime anterior. 
Com maior razão, todavia, a transformação da base material da sociedade burguesa somente em escala muito limitada pode ser objeto de atos de vontade e decisões superestruturais, condicionada como está pelo desenvolvimento das forças produtivas. $\mathrm{O}$ drama do chamado socialismo real deriva do que partiu de condições materiais e espirituais muito diferentes e tentou (muitas vezes por pressão externa) superá-las prematuramente.

Isto não implica menosprezar o fator subjetivo. A luta ideológica é um elemento essencial em um período de transição e utopias.

Logicamente que o proletariado estabelecido por Marx não é o mesmo que o dos dias atuais e nem mesmo também o é a conjuntura política que favorecia outrora a possibilidade de rupturas drásticas com o sistema - como na antiga Guerra Fria. Entretanto, as condições dos precarizados de hoje ou da "ralé" - utilizando de termos de Souza ${ }^{26}$, autor que corrobora as teses de Unger - apresentam contemporaneamente os mesmos obstáculos intransponíveis para transcender a cultura do capital (ou domínio simbólico).

Esta, por sinal, parece ser uma das tarefas mais árduas do período de transição, como a entendia Lenin, ao apresentar a questão da revolução cultural ${ }^{27}$. Não há dúvida de que o fracasso nesse terreno também foi uma das causas principais da crise que derrotou o socialismo real, cabendo-lhe, pois, lugar destacado na reflexão marxiana ${ }^{28}$.

É importante salientar ainda que o capitalismo se caracteriza, desde a sua origem, por sua vocação internacional, o que faz do mercado mundial instância privilegiada para o desenvolvimento de suas contradições. Isso corresponde a uma fuga para adiante, o que significa que o capitalismo não pode contar com o mercado mundial para superar efetivamente suas contradições, mas somente para ampliar o espaço em que elas ocorrem e, portanto, torná-las cada vez mais universais. Assim, imaginar a desagregação da propriedade privada é mais um exercício contemplativo do que factível, pois o que se verifica nos dias de hoje é exatamente o seu oposto. Ou seja, o aumento da concentração de oligopólios e consequentemente da concentração de riqueza alavancada por aumento de desemprego e pauperização da classe trabalhadora.

A conquista de novos territórios e a extensão de seu império a um número crescente de povos, processo que começa já na fase da acumulação primitiva e continua ao longo de seu desenvolvimento, permitem amenizar o perfil acentuado que suas contradições adquirem no centro do sistema, à custa da transferência para a periferia de seu potencial explosivo e autodestrutivo. Essa é a razão pela qual a ruptura com o capitalismo e a passagem para o socialismo começaram nos países mais atrasados, onde a exploração capitalista dispensava artifícios e disfarces União Soviética, Cuba, Nicarágua, Angola, Vietnã, China -, além de se exercer sobre

26 SOUZA, Jessé. Op. cit., 2006.

27 GARCIA, A. Lenin y la revolución cultural. México: Editorial Era, I975.

28 HOBSBAWM, Eric. A era dos extremos: O breve século XX. São Paulo: Companhia das Letras, I995; MARINI, Ruy Mauro e MILLÁN, Márgara. La teoría social latinoamericana: Cuestiones contemporáneas. México: unam/ fcpys/cela, I996. 
uma massa de trabalhadores ainda pouco submetidos à ideologia burguesa. O que acarreta duas consequências para o socialismo nascente: I) implantar-se sobre uma base material incipiente, pouco capacitada para enfrentar a competição com o mundo capitalista; e 2) depender da mobilização de povos que não tiveram acesso à plenitude da cultura burguesa, ainda que apresentassem muitos de seus vícios. Ao contrário, sua cultura estava marcada pela desigualdade e pelo valor de troca, sendo-lhes, portanto, fácil assimilar o que o capitalismo lhes oferecia de pior: a possibilidade de se oprimirem e se explorarem mutuamente, movidos pela ambição de possuir bens e, sobretudo, dinheiro.

Alterar esse atual estado de coisas é tarefa árdua e dificultosa. Ao contrário do que pressupõem Unger e seus adeptos, não consideramos a possibilidade de mudanças promissoras de forma endógena. A gênese do sistema e sua mola propulsora são desiguais e perversas. Imaginar mudanças profundas sem nenhum tipo de trauma ou rupturas é considerar a possibilidade de confluência de interesses de atores que sequer se reconhecem. Nesse sentido, a episteme das ciências sociais dos últimos duzentos anos parece que ainda tem muito a nos ensinar.

\section{CONSIDERAÇõES FINAIS}

Ao finalizar este breve trabalho, torna-se fundamental expor que as questões salientadas tiveram como objetivo principal proporcionar um escorço sobre um novo debate teórico que, longe de contemplar toda a sua dimensão, visa, primordialmente, contribuir para a confrontação de ideias.

De acordo com o exposto, é possível verificar que a perspectiva conceitual ungeriana ainda está em processo de construção, o que a torna aberta a críticas, tendo, por sua vez, também uma característica bem estimulante/desafiadora, já que se refere a um exercício e proposta que tem por finalidade conceber novos comportamentos, estruturas e posturas sociopolíticas.

Este trabalho tenta estabelecer diálogos provocativos perante as teses de Unger. Nesse sentido, tornar-se-á necessário expor, de forma conclusiva, algumas observações, até mesmo como estímulo a possíveis réplicas ao conteúdo aqui exposto.

Uma característica que abre lacuna para questões e possíveis críticas, dá-se quando na verificação do conceito de experimentalismo democrático - "democracia mobilizadora” -, constata-se uma miríade de pressupostos e estágios para a sua consolidação. Sua construção que, vez por outra, toma e nega alguns pressupostos marxianos, denominando-a de engessamento a uma lei natural histórica inexistente, cai no mesmo equívoco, demonstrando-se tão ou mais etapista que a perspectiva outrora criticada.

Unger, ao se escorar e exaltar a inventividade da criação do homem como a energia para uma alternativa democrática, flertando com o pressuposto marxiano clássico de que o "homem é autor de sua própria história”, não absorve a segunda parte da frase 
de Marx, que diz literalmente, que estes "não a fazem de livre e espontânea vontade, pois não são eles quem escolhem as circunstâncias sob as quais elas são realizadas"29.

As críticas acima, no entanto, não desqualificam a teoria social posta por Unger, que se coloca inevitavelmente como uma novidade para repensar os pressupostos ideológicos das teorias vinculadas à esquerda e da direita, principalmente no atual cenário brasileiro. A dúvida é se o autor, ao revelar a influência da teoria marxiana em suas reflexões, está mais inclinado a dar importância a emancipação humana ou se sua prevalência vai apenas ao encontro de uma nova roupagem do laissez faire - propósito básico do liberalismo econômico.

Além do mais, Unger, ao exaltar a criação humana atrelada à importância do direito na criação de novas alternativas institucionais, não consegue convencer o leitor de seu caráter universalista. A crença na moralidade do indivíduo - pressuposto que flerta com a ética filosófica helênica - também é sobressaltada em demasia na teoria social ungeriana e a ideologia liberal que este critica como incompleta - por não entregar tudo o que prometera - não parece se completar, a partir de seu pressuposto alternativo. Para os presentes autores, a questão aqui colocada necessita ser mais bem explorada, e soluções criativas ainda precisam ser colocadas "à prova”. É fato que o primeiro passo já foi dado - por Unger. Esperamos otimistamente que demais trabalhos surjam, tendo o mesmo objetivo que este esforçou em exercer o princípio da falseabilidade do conhecimento.

No mais, salientamos que as reflexões aqui realizadas não partem na direção de desconsiderar as teses de Unger. Pelo contrário, a intenção é fomentar o que consideramos o vital de sua obra: colocar em suspensão alguns pressupostos outrora muito sedimentados na reflexão das ciências humanas brasileira. Portanto, dialogar e discordar dos preceitos teóricos aqui apresentados reflete-se, em nosso ponto de vista, como uma necessidade e uma forma respeitosa de abordar os conceitos trabalhados pelo autor.

\section{SOBRE OS AUTORES}

WILLIAM MELO é doutorando em Ciência Política (Unicamp); mestre em Administração Pública (FGV); graduado em Ciências Sociais (UFF) e professor colaborador da FGV-IDE, UFRJ e CEDERJ/CEFET-RJ. (Niterói, Rio de Janeiro, Brasil.).

FABIANA MALHA RODRIGUES é pós-doutora em Educação (UFMG); doutora em História (UFF); mestre em História (UFF); graduada em História (UFF) e professora do CEPERJ. (Niterói, Rio de Janeiro, Brasil.).

29 MARX, Karl. O I8 de brumário de Luís Bonaparte. São Paulo: Boitempo, 20II, p. 25. 


\section{REFERÊNCIAS BIBLIOGRÁFICAS}

ALTAMIRA, César. Os marxismos do novo século. Rio de Janeiro: Civilização Brasileira, 2008.

ANDERSON, Perry. The zone of engagement. Londres: New Left Books, I992.

DAHL, Robert. Prefácio à teoria democrática. Rio de Janeiro: Zahar, I989.

. Poliarquia: Participação e oposição. São Paulo: Edusp, I997.

DRYZEK, John. Deliberative democracy and beyond: liberal, critics, contestations. Oxford: Oxford University Press, 2000.

GARCIA, A. Lenin y la revolución cultural. México: Editorial Era, I975.

HOBSBAWM, Eric. A era dos extremos: O breve século XX. São Paulo: Companhia das Letras, I995.

MARINI, Ruy Mauro; MILLÁN, Márgara. La teoría social latinoamericana: Cuestiones contemporáneas. México: unam/fcpys/cela, I996.

MARX, Karl. O I8 de Brumário de Luís Bonaparte. São Paulo: Boitempo, $20 I I$.

PATEMAN, Carole. Participação e teoria democrática. Rio de Janeiro: Paz e Terra, I992.

SABEL, Charles. Dewey, democracy and democratic experimentalism. Contemporary pragmatism, vol. 9, n. 2, 2012.

SOUZA, Jessé. A invisibilidade da desigualdade brasileira. Belo Horizonte: Editora da UFMG, 2006. . A ralé brasileira: quem é e como vive. Belo Horizonte: Editora da UFMG, 2009.

. Os batalhadores brasileiros: Nova classe média ou nova classe trabalhadora? Belo Horizonte: Editora da UFMG, 2010.

. A tolice da inteligência brasileira: Ou como o país se deixa manipular pela elite. São Paulo: Leya, 2015.

TEIXEIRA, Carlos Sávio. A esquerda experimentalista: A análise da teoria política de Unger. Tese (Doutorado). São Paulo: Universidade de São Paulo, 2009.

UNGER, Roberto Mangabeira. Democracia realizada: A alternativa progressista. São Paulo: Boitempo, I999.

Política: Os textos centrais. São Paulo: Boitempo, 200I.

. O direito e o futuro da democracia. São Paulo: Boitempo, 2004 .

. Necessidades falsas. São Paulo: Boitempo, 2005.

. A constituição do experimentalismo democrático. Revista de Direito Administrativo, vol. 257, maio-ago. 20II. 